\title{
The Study of Multilayer Graphene Membrane Performance in 02 Purification Process: Molecular Dynamics Simulation
}

Mostafa Jafari

University of Tehran

Roozbeh Sabetvand ( $\nabla$ r.sabetvand@gmail.com )

Amirkabir University of Technology

\section{Research Article}

Keywords: Graphene, Atomic membrane, Molecular dynamics, Purification process, Oxygen, Carbon dioxide

Posted Date: December 8th, 2021

DOI: https://doi.org/10.21203/rs.3.rs-971670/v1

License: (c) (i) This work is licensed under a Creative Commons Attribution 4.0 International License.

Read Full License 


\title{
The Study of Multilayer Graphene Membrane Performance in $\mathrm{O}_{2}$ Purification Process: Molecular Dynamics Simulation
}

\author{
Mostafa Jafari ${ }^{1}$, Roozbeh Sabetvand ${ }^{2 *}$ \\ ${ }^{1}$ Institute of Liquefied Natural Gas (I-LNG), School of Chemical Engineering, College of \\ Engineering, University of Tehran, Tehran, Iran \\ ${ }^{2}$ Department of Energy Engineering and Physics, Faculty of Condensed Matter Physics, Amirkabir \\ University of Technology, Tehran, Iran \\ *Corresponding author E-mail: r.sabetvand@gmail.com
}

\begin{abstract}
We use molecular dynamics (MD) method to describe the atomic behavior of Graphene nanostructure for Oxygen molecules $\left(\mathrm{O}_{2}\right)$ separation from Carbon dioxide $\left(\mathrm{CO}_{2}\right)$ molecules. Technically, for the simulation of graphene-based membrane and $\mathrm{O}_{2}-\mathrm{CO}_{2}$ gas mixture, we used Tersoff and DREIDING force fields, respectively. The result of equilibrium process of these structures indicated the good stability of them. Physically, this behavior arises from the appropriate MD simulation settings. Furthermore, to describe the purification performance of graphene-based membrane, we report some physical parameters such as purification value, impurity rate, and permeability of membrane after atomic filtering process. Numerically, by defined membranes optimization, the purification value of them reach to $97.31 \%$. Also, by using these atomic structures the $\mathrm{CO}_{2}$ impurity which passed from graphene-based membrane reach to zero value.

Keywords: Graphene; Atomic membrane; Molecular dynamics; Purification process; Oxygen; Carbon dioxide;
\end{abstract}

\section{Nomenclature}

$\mathrm{F}_{\mathrm{ij}}, \quad$ Atomic force between $\mathrm{i}$ and $\mathrm{j}$ atoms;

$\mathrm{V}_{\mathrm{ij}}, \quad$ Potential energy between $\mathrm{i}$ and $\mathrm{j}$ atoms;

$\mathrm{m}$, Atomic mass;

$r_{c}, \quad$ Cut-off radius; 
$\mathrm{r}_{\mathrm{ij}}, \quad$ Distance between $\mathrm{i}$ and $\mathrm{j}$ atoms;

$\mathrm{t}$, Time step in molecular dynamics simulation;

$\mathrm{T}$ Temperature in molecular dynamics simulation;

$\mathrm{V} \quad$ Atomic velocity;

$\mathrm{N}_{\text {atom, }}$ Number of atoms;

$\mathrm{N}_{\mathrm{sf}} \quad$ Degree of freedom;

$\mathrm{k}_{\mathrm{B}}$, Boltzman constant;

$\mathrm{r}_{0} \quad$ Equilibrium bond length;

\section{Greek symbols}

$\varepsilon$ Energy constant in Lennard-Jones function;

$\sigma, \quad$ Length constant in Lennard-Jones function;

$\theta_{0} \quad$ Equilibrium angle;

\section{Introduction}

Atomic membranes are a new class of low-dimensional, free standing, physically stable, and virtually impermeable materials [1-4]. The common 2D atomic membrane is graphene nanosheet, a two-dimensional lattice entirely made of carbon atoms, but other interesting structures such as the multilayer graphene offer new properties [5-8]. Structurally, graphene nanosheet is a layer of carbon atoms which are bonded together with covalent interaction in honeycomb lattice. This atomic structure shows promising properties including a high specific surface area, good thermal conductivity, proper mechanical behavior, and excellent charge mobility $[9,10]$. Due to these interesting properties, this atomic layer has remained at the core of scientific research since its advent, with many of its successful accomplishments being transformed into various applications. Today, graphene-based nanostructures are used commonly in fuel cells [11, 12], supercapacitor [13, 14], capacitive deionization [15-17], desalination [18-20]. Furthermore, graphenebased membranes are the other class of this atomic structure applications. These atomic membranes are capable of creating an appropriate barrier when dealing with liquids and gasses particles. Graphene-based membranes effectively separate target atoms from liquid and gasses environment. Physically, due to the repulsive interaction of the $\pi$-bond orbital electron distrobution in graphene nanosheet, this atomic structure is not permeable to liquid or gas environment [21].

These practical properties of graphene membrane can be studied with experimental and 
theoretical approaches. Molecular Dynamics (MD) method is one of the important methods in the atomic study of various nanostructures [22-25]. Previously, this computational method used for graphene-based membrane study. Cohen-Tanugi et al. [26] showed that nanoporous graphene membranes can remove $\mathrm{NaCl}$ from $\mathrm{H}_{2} \mathrm{O}$ molecules. In their work, simulation results show the single layer membranes delivery capacity reach to $66 \mathrm{~L} /$ $\left(\mathrm{cm}^{2} \cdot\right.$ day.MPa). In other work, this research group used single layer graphene as a reference structure to explore the possibility of multilayer graphene membranes [27]. The result of this computational work show the appropriate properties of multilayer grapgene structures as atomic membrane. Konatham et al. [28] described the transport of $\mathrm{H}_{2} \mathrm{O}$ molecules and atomic ions in the pores of the graphene nanosheet. The MD results indicated the use of hydroxylated graphene pores can improve the membrane efficiency for actual applications. Also, Wang et al. [29] used graphene nanosheet on polyacrylonitrile matrix to introduce an effective graphene oxide membrane. It was found that with graphene oxide thickness increasing, the $\mathrm{H}_{2} \mathrm{O}$ molecules flux decreased appreciably. So, due to the appropriate performance of MD simulations in the study of graphene-based membranes behavior, in this work we use of this approach to describe of multilayer (3-layers) graphene membrane performance in $\mathrm{O}_{2}$ purification process from $\mathrm{O}_{2}-\mathrm{CO}_{2}$ gas mixture for the first time. In our MD simulations, the distance between various sheets and porous radius changes to designing optimized atomic membrane for $\mathrm{O}_{2}$ molecules purification process to actual applications.

\section{Computational Method}

In this MD study, graphene membrane and initial mixture gas $\left(\mathrm{O}_{2}-\mathrm{CO}_{2}\right)$ interact with each other for the $\mathrm{t}=2 \mathrm{~ns}$. This atomic procedure determines the graphene membrane filtering performance in $\mathrm{O}_{2}$ purification process. In our computational approach, simulations were done by LAMMPS package [30-33]. By using this computational package, multi-layer graphene membrane and $\mathrm{O}_{2}-\mathrm{CO}_{2}$ gas mixture simulated as $\mathrm{C}, \mathrm{H}$, and $\mathrm{O}$ atoms arrangement as depicted in Figure 1. This atomic structure depicted by OVITO (Open Visualization Tool) software [34]. Computationally, in depicted atomic structures, fix boundary 
conditions were used in $\mathrm{x}$ direction and periodic style implemented to $\mathrm{y}$ and $\mathrm{z}$ directions [35]. After atomic modeling, NVT ensemble used in our MD simulations to equilibrate the temperature of structures $[36,37]$. This computational ensemble equilibrate the multilayer membrane and gas mixture at $\mathrm{T}_{0}=300 \mathrm{~K}$ with 0.001 damping value for temperature.

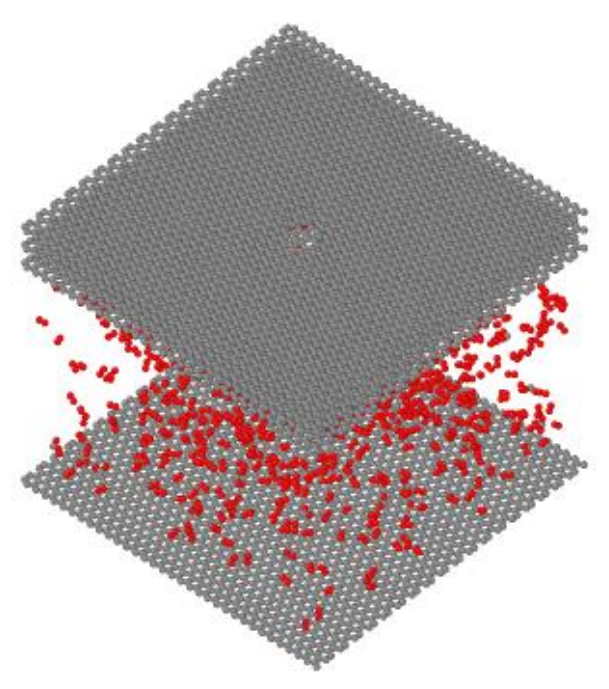

a 


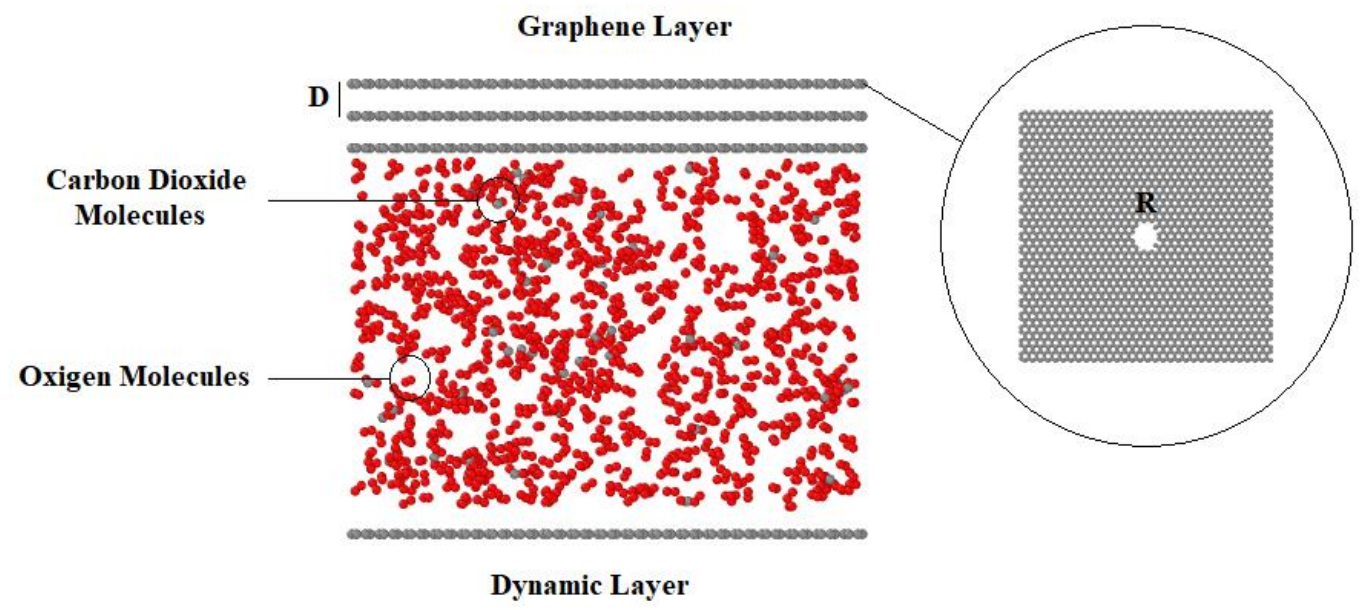

b

Figure. 1. Schematic of a) atomic structures arrangement in MD simulation box, and b) atomic properties of simulated structures with LAMMPS package.

Atomic force-field is an important parameter in common MD simulations. To simulate the atomic structures inside MD box, we use DREIDING and Tersoff force-fields [38, 39]. In DREIDING force-field, the atomic interactions were presented by non-bonded and bonded terms. The Non-bond term in atomic structures simulation defined by the Lennard-Jones (LJ) equation (12-6 type) as reported in equation 1. Historically, this mathematical function was introduced by John Lennard Jones for the first time as equation (1) [40]:

$E(r)=4 \varepsilon\left[\left(\frac{\sigma}{r_{i j}}\right)^{12}-\left(\frac{\sigma}{r_{i j}}\right)^{6}\right], \quad r \ll r_{c}$

In equation (1), $\varepsilon$ is the depth of the potential well, $\sigma$ is the distance at which the potential function is zero and $\mathrm{r}_{\mathrm{ij}}$ is the atomic distance. These physical parameters selected with type of atoms in simulated structures. So, these parameters value for all atoms in our MD simulation reported in Table 1 [39]. 
Table 1. The $\varepsilon$ and $\sigma$ constants for LJ interactions in our MD simulation box [39].

\begin{tabular}{|c|c|c|}
\hline Type of atoms & $\boldsymbol{\sigma}(\boldsymbol{\AA})$ & $\boldsymbol{\varepsilon}(\mathbf{k c a l} / \mathbf{m o l})$ \\
\hline $\mathrm{C}$ & 4.180 & 0.3050 \\
\hline $\mathrm{H}$ & 3.200 & 0.0100 \\
\hline $\mathrm{O}$ & 3.710 & 0.4150 \\
\hline
\end{tabular}

The bonded term of atomic interactions consist of simple and angle strengths. The bond and angle strengths in DREIDING force-field is calculated by harmonic oscillator formalism as equations (2) and (3), respectively [39]:

$$
\begin{aligned}
& E_{r}=\frac{1}{2} k_{r}\left(r-r_{0}\right) \\
& E_{\theta}=\frac{1}{2} k_{\theta}\left(\theta-\theta_{0}\right)
\end{aligned}
$$

in equations (2) and (3), $K_{r}$ and $K_{\theta}$ are the constants of harmonic oscillator. Also, $r_{0}$ and $\theta_{0}$ are the equilibrium value of bond length and angle, respectively. Harmonic oscillator constants $\left(\mathrm{K}_{\mathrm{r}}\right.$ and $\left.\mathrm{K}_{\theta}\right)$ in DREIDING force-field set to $700(\mathrm{kcal} / \mathrm{mol}) / \AA^{2}$ for each atomic bond and $100(\mathrm{kcal} / \mathrm{mol}) /$ degree $^{2}$ for all bond angle bend. Furthermore, the equilibrium value of bond length and angle in our simulated structures listed in Table 2 [39].

Table 2. The $\mathrm{r}_{0}$ and $\theta_{0}$ values for the bond strength and angle bend of simulated structures by MD method [39].

\begin{tabular}{|c|c|c|}
\hline Parameter & ro $(\AA)$ & $\boldsymbol{\theta}$ (degree) \\
\hline C-O bond & 1.420 & - \\
\hline O-O bond & 1.310 & - \\
\hline O-C-O angle & - & 109.471 \\
\hline
\end{tabular}

As mentioned before, Tersoff force-field used for $\mathrm{C}$ atoms interaction in graphene nanosheets as below [38]: 
$E=\frac{1}{2} \sum_{i} \sum_{j \neq i} E_{i j}$

$E_{i j}=f_{C}\left(r_{i j}\right)\left[f_{R}\left(r_{i j}\right)+b_{i j} f_{A}\left(r_{i j}\right)\right]$

where $f_{R}$ is a two-body term and $f_{A}$ includes three-body interactions. The summations in equation (5) are over all neighbors $\mathrm{j}$ and $\mathrm{k}$ of atom $\mathrm{i}$ within a cutoff radius. After defining an appropriate force-field to $\mathrm{O}_{2}-\mathrm{CO}_{2}$ gas mixture and graphene-based membrane, $\mathrm{MD}$ study was fulfilled. Then, to describe the atomic structures time evolution inside MD box, Newton's law's is used as the gradient of selected force-fields [35]:

$F_{i}=\sum_{i \neq j} F_{i j}=m_{i} \frac{d^{2} r_{i}}{d t^{2}}=m_{i} \frac{d v_{i}}{d t}$

$F_{i j}=-\nabla V_{i j}$

From these base equations, the atomic momentum $P_{i}$ can be defined as equation (8) [37]:

$P_{i}=m_{i} v_{i}$

In the stated equations, to integrate the Newton's law's, the association of equation (6) is done by the Velocity-Verlet algorithm as below [35]:

$r(t+\delta t)=r(t)+v(t) \delta t+\frac{1}{2} a(t) \delta t^{2}$

$v(t+\delta t)=v(t)+\frac{1}{2}[a(t)+a(t+\delta t)] \delta t$

In equations (9) and (10), $r(t+\delta t), v(t+\delta t)$ is the position and velocity of atoms in $\mathrm{t}+\delta \mathrm{t}$ and $r(t), v(t)$ is the value of these physical quantities in t. Furthermore, in MD simulation approach, Gaussian distribution is implemented for temperature calculating in atomic arrangement as equation (11) [35]:

$\frac{3}{2} k_{B} T=\frac{1}{N_{\text {atom }}} \sum_{i=1}^{N} \frac{1}{2} m v_{i}^{2}$

Finally, the instantaneous temperature variation is calculated from equation (12) [35]:

$T(t)=\sum_{i}^{N} \frac{m_{i} v_{i}^{2}(t)}{k_{B} N_{s f}}$

Where, $\mathrm{N}_{\mathrm{sf}}$ is the degree of freedom of the atomic systems. According to the reported descriptions, MD simulations in current computational study carried out as below:

Step 1: $\mathrm{CO}_{2}-\mathrm{O}_{2}$ gas mixture and graphene-based membrane was simulated with 
DREIDING and Tersoff force-fields and equilibrated by NVT ensemble for 1000000 time steps with $\Delta \mathrm{t}=1 \mathrm{fs}$. For this purpose, atomic structures temperature set at $\mathrm{T}_{0}=300 \mathrm{~K}$ as initial condition. After, atomic structures reached to equilibrium phase, the stability of them reported by temperature and potential energy calculating.

Step 2: Next, atomic purification process settings implemented to equilibrated structures for 1000000 time steps with NVE ensemble ( $t=1 \mathrm{~ns}$ ). For this purpose, dynamic graphene sheet displace in MD simulation box with constant velocity (see Figure 2). After this process, physical parameters such as: purification and permeability values reported to describe the atomic behavior of graphene-based membrane in $\mathrm{O}_{2}$ purification process.

\section{Results and Discussion}

\subsection{Equilibration Process of Atomic Structures}

In the first step of our computational work, the atomic behavior of $\mathrm{O}_{2}-\mathrm{CO}_{2}$ gas mixture and graphene-based membrane was studied at initial temperature $\left(\mathrm{T}_{0}=300 \mathrm{~K}\right)$ for $1 \mathrm{~ns}$. Our simulation results, showed the initial arrangement of particles in simulation box adopted with DREIDING and Tersoff force-fields [38, 39]. This atomic phase of simulated structures reported by temperature and potential energy calculations. The simulated structures temperature changes as a function of simulation time as depicted in Figure 2. From calculated results, we conclude the atomic structures equilibrated after 1000000 time steps ( $\mathrm{t}=1 \mathrm{~ns}$ ). Physically, this thermal equilibrium arises from atomic oscillation reducing which indicted our MD simulation settings validity [35]. Also, Figure 3 shows the potential energy changes in atomic systems as a function of MD simulation time in this computational step. From this figure, we conclude the simulated structures potential energy converged after 1000000 time steps to constant value. Numerically, potential energy of graphene membrane and $\mathrm{CO}_{2}-\mathrm{O}_{2}$ gas mixture reached to $-399 \mathrm{eV}$ after $1 \mathrm{~ns}$. Theoretically, this physical parameter has reciprocal relation by mean distance of atoms. By increasing the potential energy magnitude, the atomic stability of target system increased. Figure 3 indicated, by increasing the initial porous radius (R) from $3 \AA$ to $5 \AA$ and $7 \AA$, the atomic system don't disrupted and so, stable phase of them can be detected after equilibrium 
process. Our calculations show the temperature of equilibrated structures reach to $300 \mathrm{~K}$ in the final step of simulations. Physically, atomic stability of initial membrane decreases by porous radius increasing. Numerically, by porous enlarging, the magnitude of potential energy parameter decreases to $-376 \mathrm{eV}$ from $-399 \mathrm{eV}$. This behavior arises from carbon atom missing in membrane structure and interatomic force (by attraction type) decreasion in defined layer system. Atomic layer distance between graphene sheets (D) is another important parameter for graphene-based membrane stability. By this parameter changes from $5 \AA$ to $7.5 \AA$ and $10 \AA$, the potential energy of the total atomic system decreases to $395 \mathrm{eV}$ and $-390 \mathrm{eV}$, respectively. This behavior arises from mutual interaction between carbon atoms which cause saving energy in MD simulation box. We can say the atomic stability of simulated membrane decreased by these potential energies magnitude decreasing.

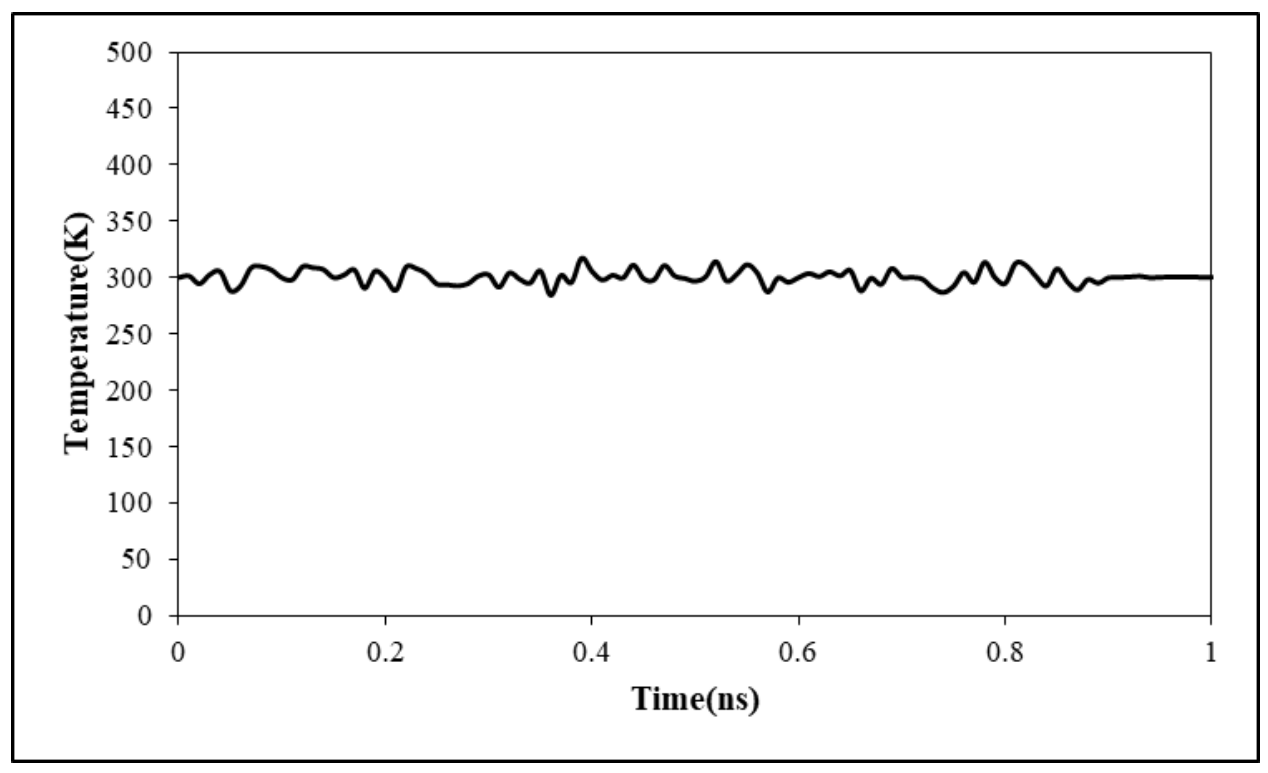

Figure 2. Temperature changes of graphene membrane and $\mathrm{CO}_{2}-\mathrm{O}_{2}$ gas mixture as a function of $\mathrm{MD}$ simulation time. 


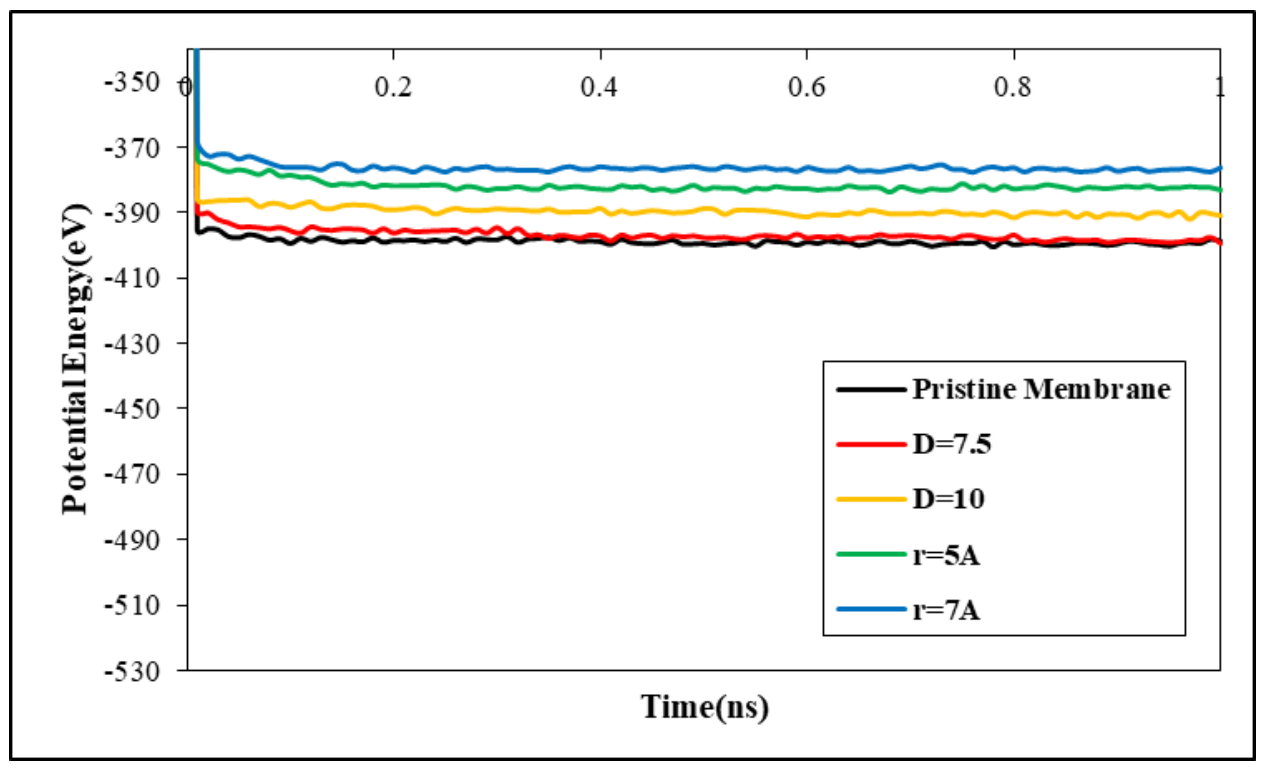

Figure 3. Potential energy changes of graphene membrane and $\mathrm{CO}_{2}-\mathrm{O}_{2}$ gas mixture as a function of porous radius and atomic layers distance.

\subsection{Atomic Behavior of Simulated Structures}

\subsubsection{Atomic Behavior of Pristine Graphene Membrane}

In this step, MD settings implemented to pristine graphene membrane to study of $\mathrm{O}_{2}$ molecules purification efficiency with this atomic arrangement. Figure 4 shows the evolution of atomic structures after 300000 time steps ( $t=0.30 \mathrm{~ns})$. After the equilibration phase, the number of filtered $\mathrm{O}_{2}$ molecules variation as a function of MD simulation time reported in Figure 5. From this computational result, we conclude the MD simulation time $(\mathrm{t}=1 \mathrm{~ns})$ is long enough to the atomic purification process detecting. After this atomic phase, the number of $\mathrm{CO}_{2}$ molecules which passed from graphene membrane reported (see Figure 6). From our MD simulation results, the number of filtered $\mathrm{O}_{2}$ molecules reach to 591 (88.20\% ratio) which this calculated value comparable with previous reports [41, 42]. Also computed value of $\mathrm{CO}_{2}$ molecules which passed from pristine membrane is 12 molecules (17.14\% ratio). Reported atomic behavior of simulated structures in this MD simulation step show the validity of our computational settings and show the appropriate 
behavior of graphene-based membranes in atomic purification process.

Region 2

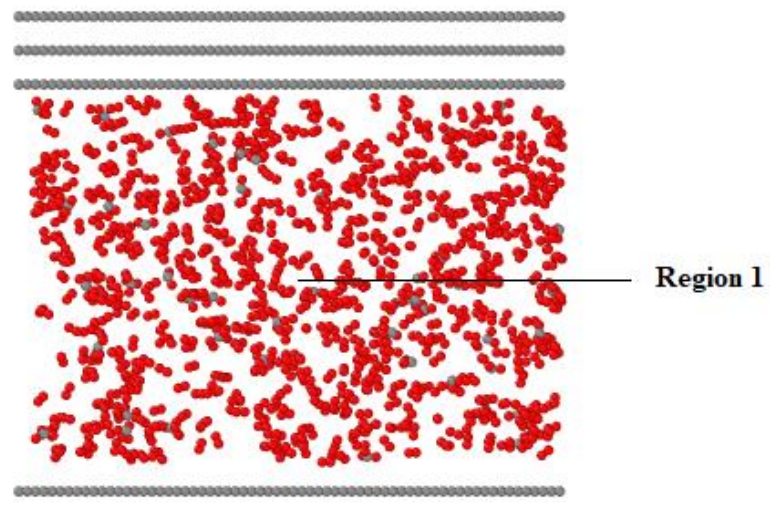

a

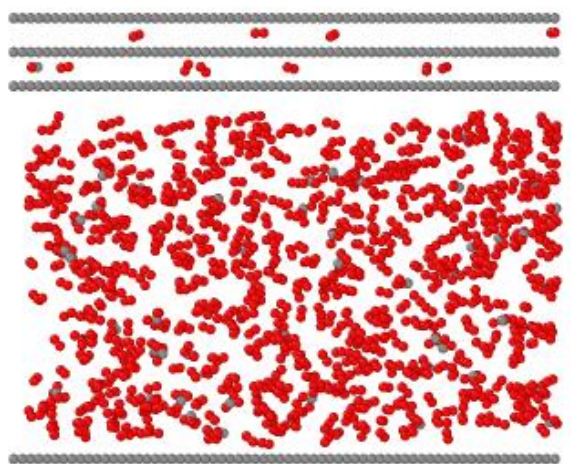

b 


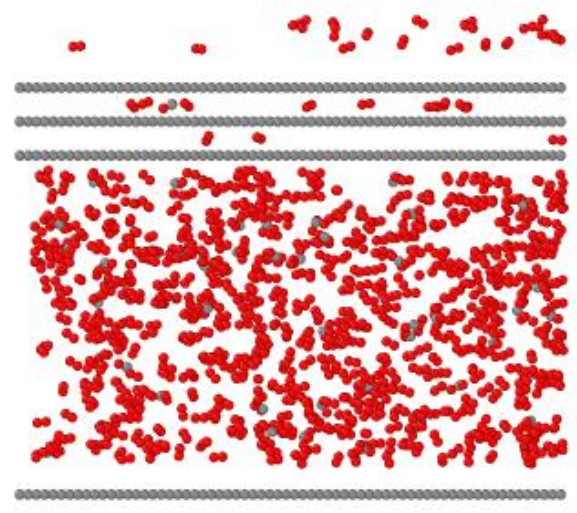

c
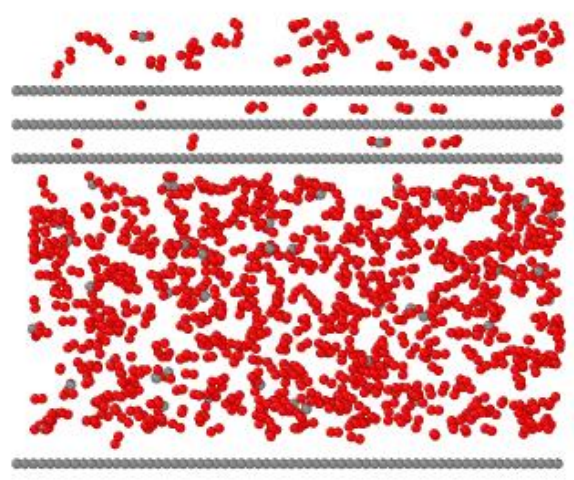

d

Figure 4. Time evolution of $\mathrm{O}_{2}-\mathrm{CO}_{2}$ gas mixture purification process with pristine graphene membrane at a) $t=0, b) t=0.1 \mathrm{~ns}, \mathrm{c}) \mathrm{t}=0.2 \mathrm{~ns}$, and d) $\mathrm{t}=0.3 \mathrm{~ns}$. 


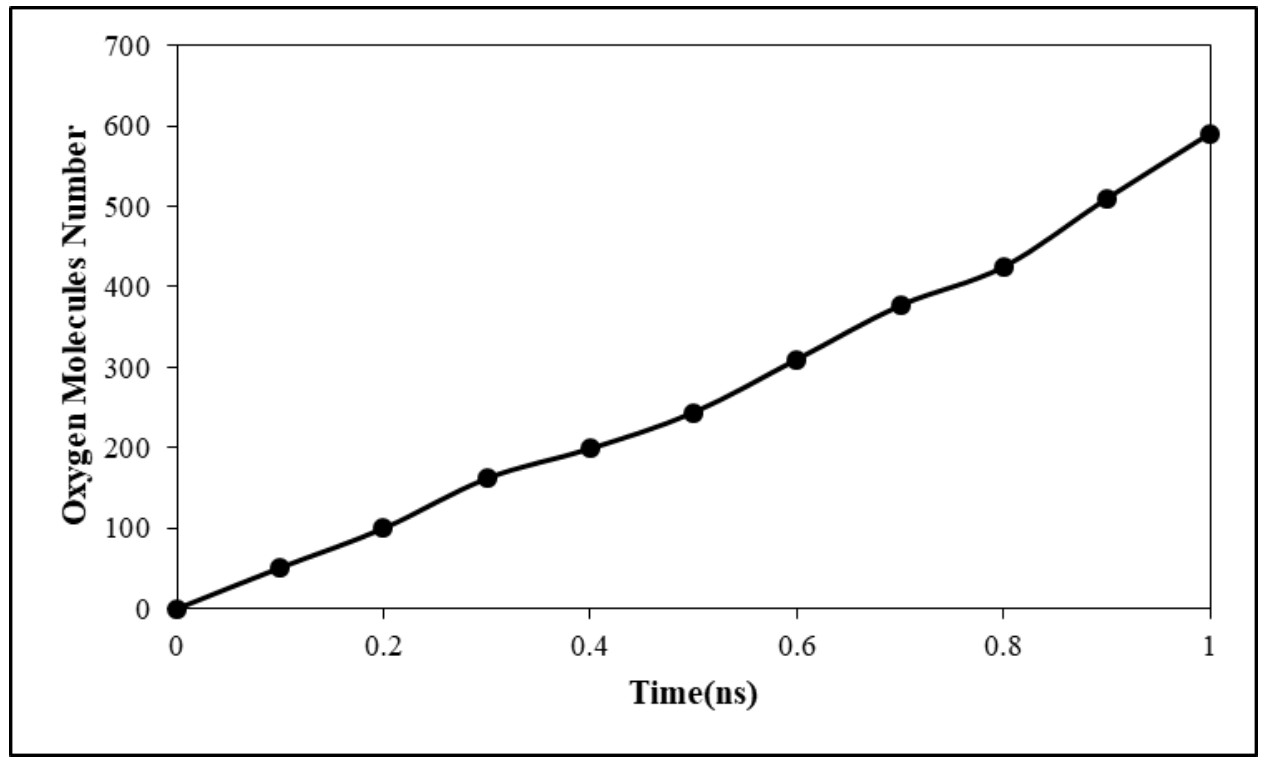

Figure 5. Number of $\mathrm{O}_{2}$ molecules which passed from pristine graphene membrane as a function of MD simulation time.

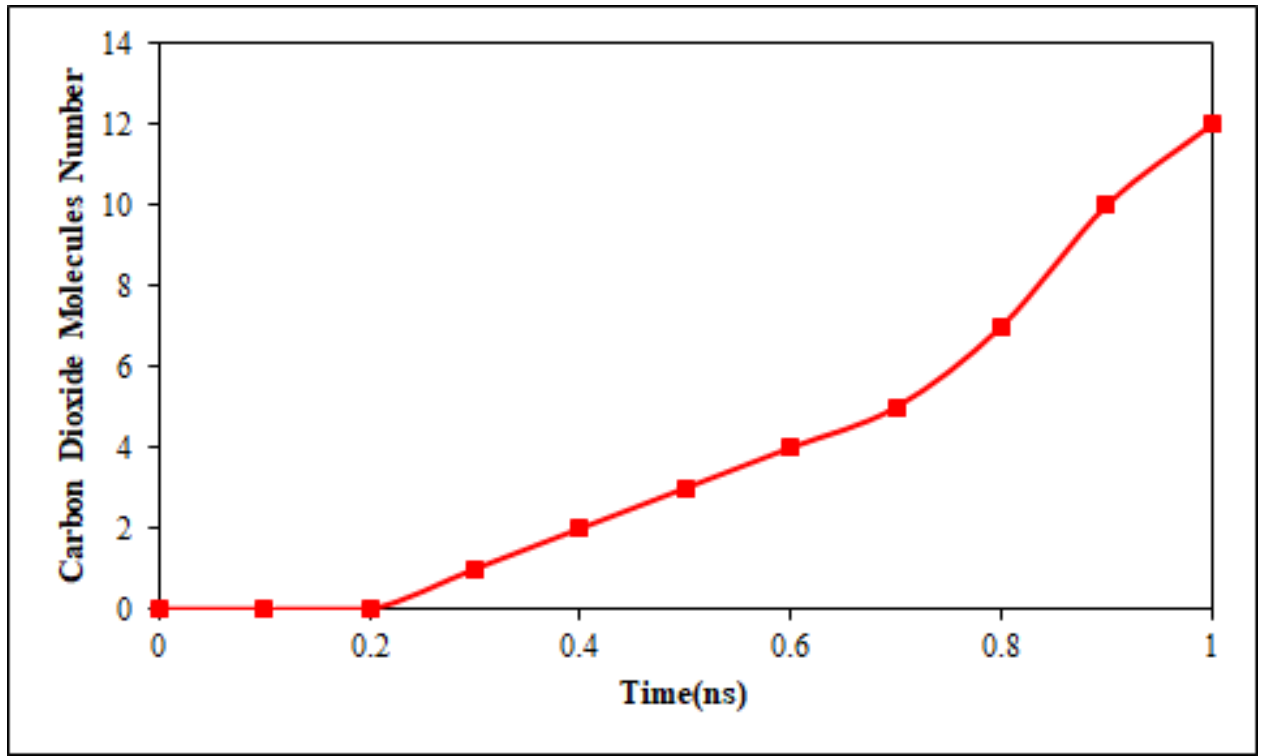

Figure 6. Number of $\mathrm{CO}_{2}$ molecules which passed from pristine graphene membrane as a function of MD simulation time.

\subsubsection{Graphene Layers Distance Effect on Atomic Behavior of Membrane}

The results of graphene layers distance effects on carbon-based membrane purification 
behavior reported in this section of our MD study. The distance of atomic layers (D) which depicted in Figure 1 are set to $5 \AA$, $7.5 \AA$, and $10 \AA$ in NVT ensemble by setting initial temperature in $\mathrm{T}_{0}=300 \mathrm{~K}$. After atomic equilibration process simulation for 1000000 time steps ( $\mathrm{t}=1 \mathrm{~ns}$ ), the atomic structure were used for atomic purification process to estimate efficiency of them in this performance. Numerically, by D parameter increasing, the number of $\mathrm{O}_{2}$ molecules which passed from carbon-based membrane decreases to 498 molecules (74.33\% ratio) as reported in Figure 7. Furthermore, the $\mathrm{CO}_{2}$ molecules elimination rate improve by $\mathrm{D}$ parameter increasing in modeled atomic membrane and the number of $\mathrm{CO}_{2}$ molecules in region 2 reach to zero after 1 ns as depicted in Figure 8. Physically, by graphene layers distance variation, the attraction force which implemented to $\mathrm{O}_{2}-\mathrm{CO}_{2}$ gas mixture changes. This type of atomic interaction decreases by $\mathrm{D}$ parameter increasing and so the efficiency of graphene membrane improved. Also, the permeability of atomic structures affected by D parameter variation. From Figure 9a we can say the maximum value of this physical parameter reach to $62 \mathrm{~L} / \mathrm{cm}^{2} / \mathrm{day} / \mathrm{MPa}$ and 43 $\mathrm{L} / \mathrm{cm}^{2} /$ day/MPa by D parameter increasing from $7.5 \AA$ to $10 \AA$, respectively. Here, the interaction energy between membrane atoms and gas mixture reported for more description of detected atomic phenomenon. This physical parameter indicated the atomic evolution of simulated structures. We report the total component of interaction energy in Figure $\mathbf{9 b}$. $\mathrm{MD}$ results show that by $\mathrm{D}$ parameter enlarging, the interaction energy between membrane and $\mathrm{O} 2-\mathrm{CO} 2$ system decreases. This behavior arises from atomic distance increasing between simulated components which by this atomic evolution the membrane efficiency decreases. As reported in Figure 9b, D parameter enlarging cause interaction energy changes from $-41.32 \mathrm{eV}$ to $-32.09 \mathrm{eV}$. By data analyzing from this section of our MD simulations, we conclude the D parameter increasing, improve the accuracy of atomic purification process and decreases the speed of this atomic phenomenon (as listed Table 3). 


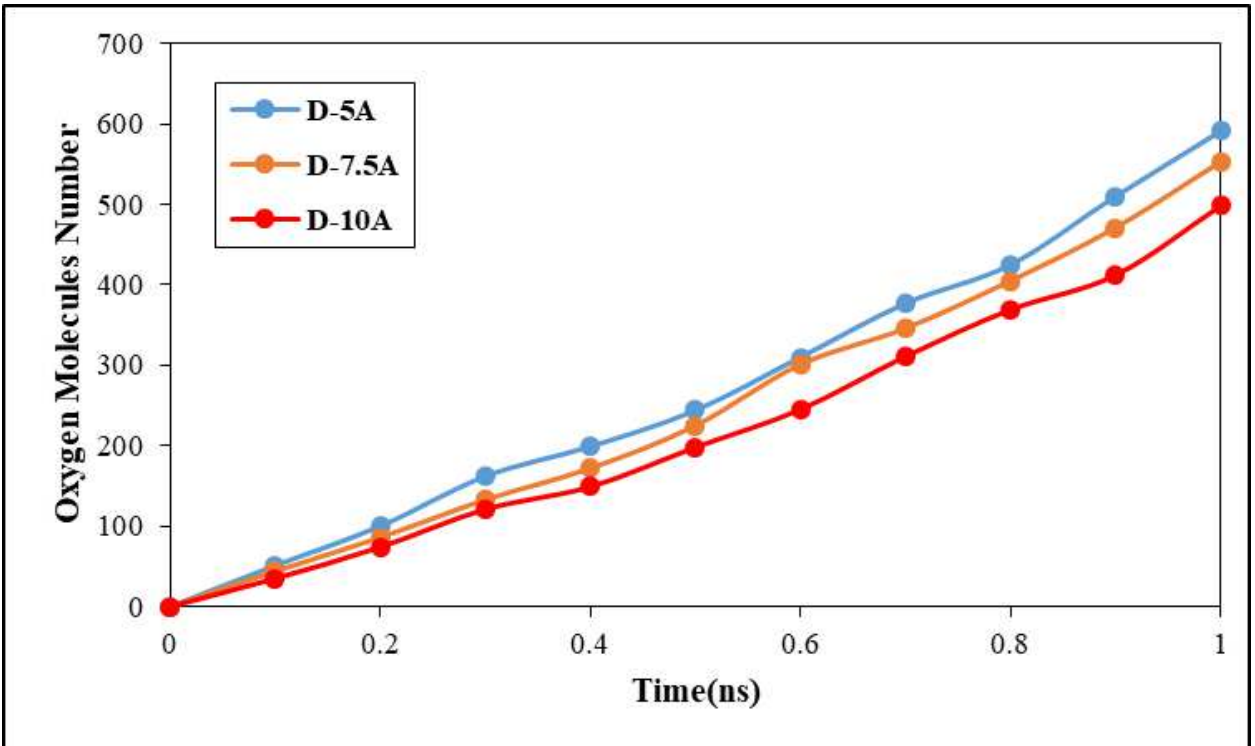

Figure 7. Number of $\mathrm{O}_{2}$ molecules which passed from pristine graphene membrane as a function of graphene layers distance (D). The total number of $\mathrm{O}_{2}$ molecules inside MD box is 670 molecules.

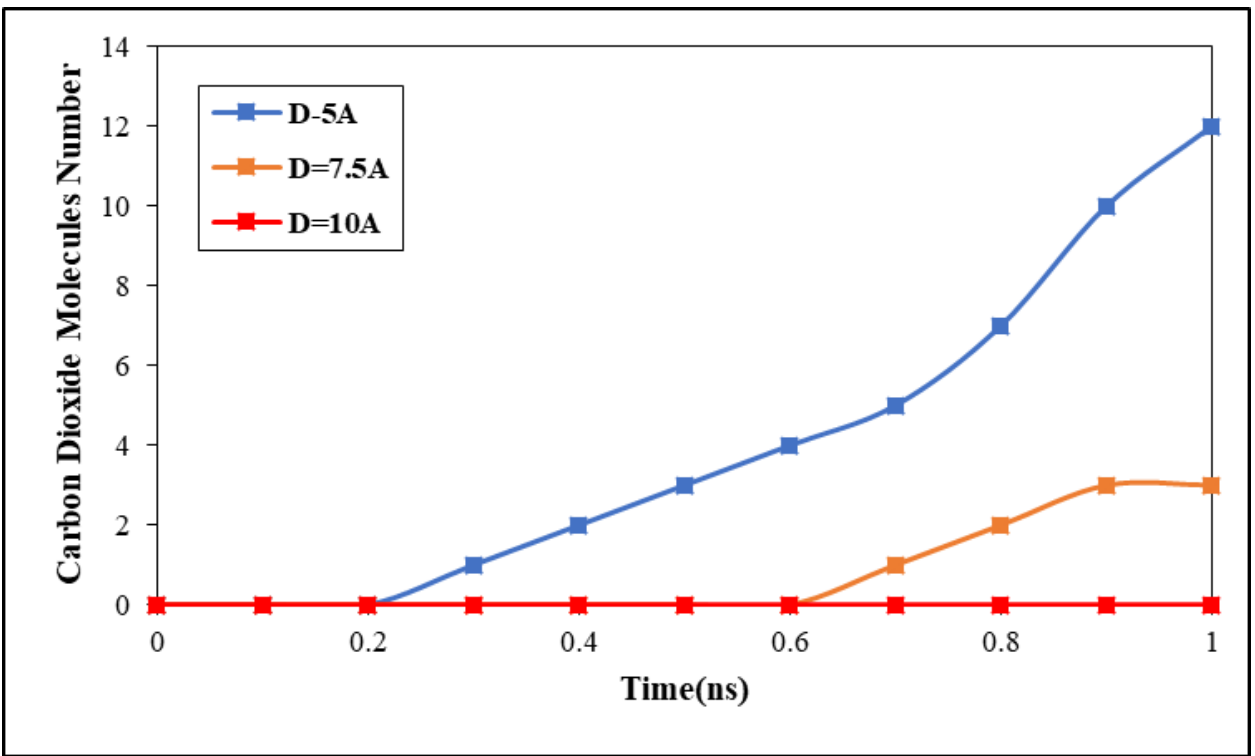

Figure 8. Number of $\mathrm{CO}_{2}$ molecules which passed from pristine graphene membrane as a function of graphene layers distance (D). The total number of $\mathrm{CO}_{2}$ molecules inside MD box is 70 molecules. 

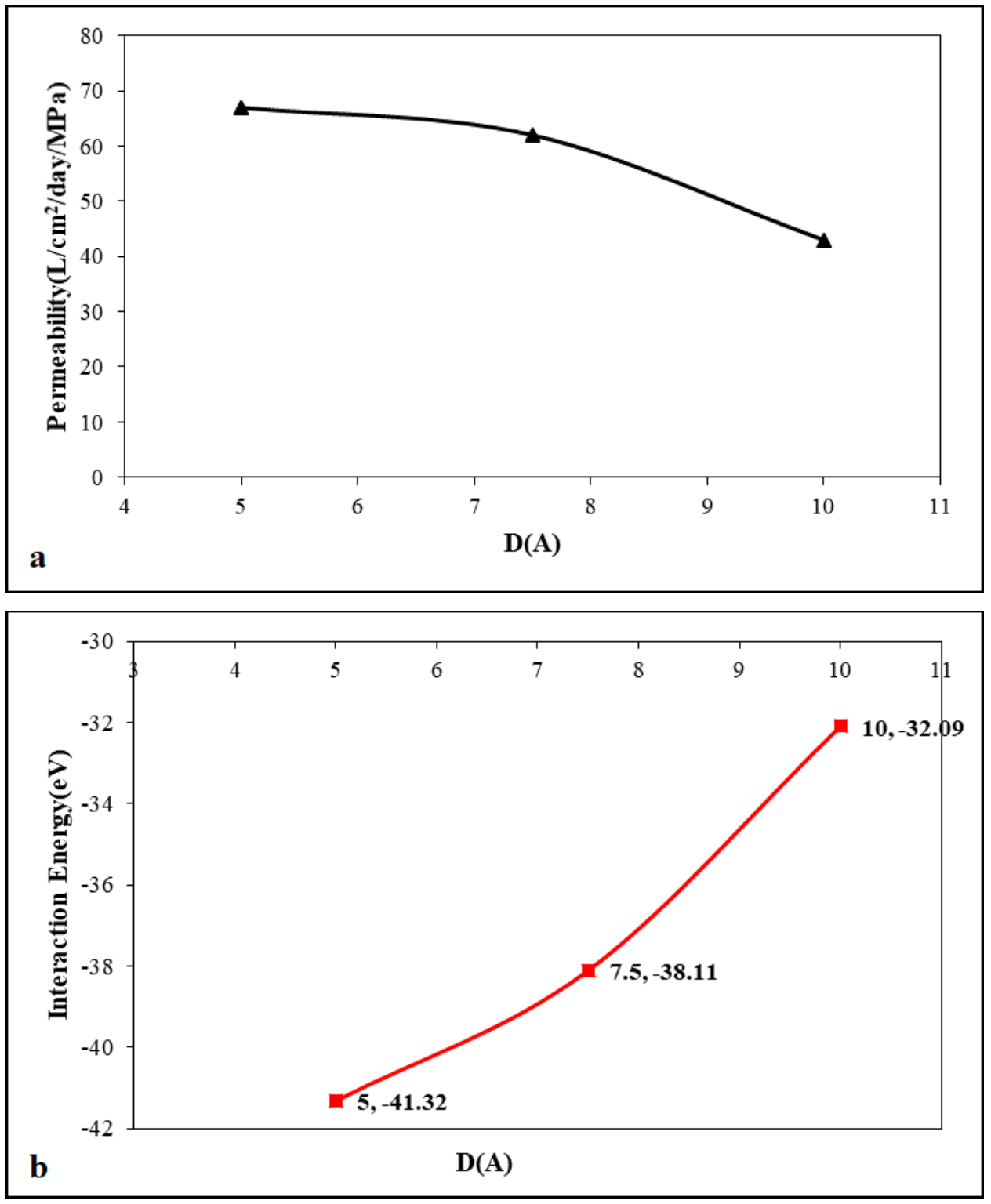

Figure 9. a) Permeability of graphene-based membrane as a function of graphene layers distance (D). b) Interaction energy between atomic membrane and gas system as a function of D parameter.

Table 3. Number of $\mathrm{O}_{2}$ and $\mathrm{CO}_{2}$ molecules which passed from graphene-based membrane and membrane permeability as a function of graphene layers distance (D).

\begin{tabular}{|c|c|c|c|}
\hline $\begin{array}{c}\text { Graphene Layers } \\
\text { Distance }(\AA)\end{array}$ & $\begin{array}{l}\text { Number of Passed } \\
\qquad \mathrm{O}_{2} \text { Molecules }\end{array}$ & $\begin{array}{c}\text { Number of Passed } \\
\mathrm{CO}_{2} \text { Molecules }\end{array}$ & Permeability $\left(\mathrm{L} / \mathrm{cm}^{2} /\right.$ day/MPa $)$ \\
\hline 5 & 591 & 12 & 67 \\
\hline 7.5 & 553 & 3 & 62 \\
\hline 10 & 498 & 0 & 43 \\
\hline
\end{tabular}




\subsubsection{Graphene Layers Porous Size Effect on Atomic Behavior of Membrane}

In the final step of our computational work, we reported the graphene layers porous size (R) effect on carbon-based membrane purification efficiency. The porous size of graphene

sheets set to $3 \AA$, $5 \AA$, and $7 \AA$ at $\mathrm{T}_{0}=300 \mathrm{~K}$. After MD equilibration process implementing for $\mathrm{t}=1 \mathrm{~ns}$, the dynamic graphene sheet move by $1 \mathrm{MPa}$ pressure and so atomic purification process fulfilled after $1 \mathrm{~ns}$. Our MD simulation results show that, by $\mathrm{R}$ parameter increasing, the number of $\mathrm{O}_{2}$ molecules in region 2 increases from 591 molecules $(88.21 \%)$ to $623(92.98 \%)$ and $652(97.31 \%)$ molecules (respectively) as reported in Figure 10. Furthermore, the $\mathrm{CO}_{2}$ molecules elimination rate getting worse by $\mathrm{R}$ parameter increasing in graphene nanosheets. Numerically, $\mathrm{CO}_{2}$ molecules elimination reach to $24.28 \%$ and $32.86 \%$ after $1 \mathrm{~ns}$ as depicted in Figure 11. Physically, by graphene layers porous size increasing, the atomic interaction between carbon atoms in membrane structure and $\mathrm{O}_{2}$ $\mathrm{CO}_{2}$ gas mixture decreased and the more molecules can be passed from graphene configuration as target membrane. The permeability of graphene membrane also affected by $\mathrm{R}$ parameter variation and the maximum value of this atomic separation factor reach to $71 \mathrm{~L} / \mathrm{cm}^{2} / \mathrm{day} / \mathrm{MPa}$ and $77 \mathrm{~L} / \mathrm{cm}^{2} / \mathrm{day} / \mathrm{MPa}$ (see Figure 12a). As previous section, interaction energy between atomic membrane and atomic gas mixture reported in Figure 12b. MD outputs in this section indicated the interaction energy get to more values by $R$ parameter enlarging. By this process occur, the number of atoms which attracted by graphene sheets increased and number of passed molecules from target membrane improved. From these calculated results, we can conclude $\mathrm{R}$ parameter increasing, decrease the accuracy of purification process and increase the speed of this atomic phenomenon as reported in Table 4. 


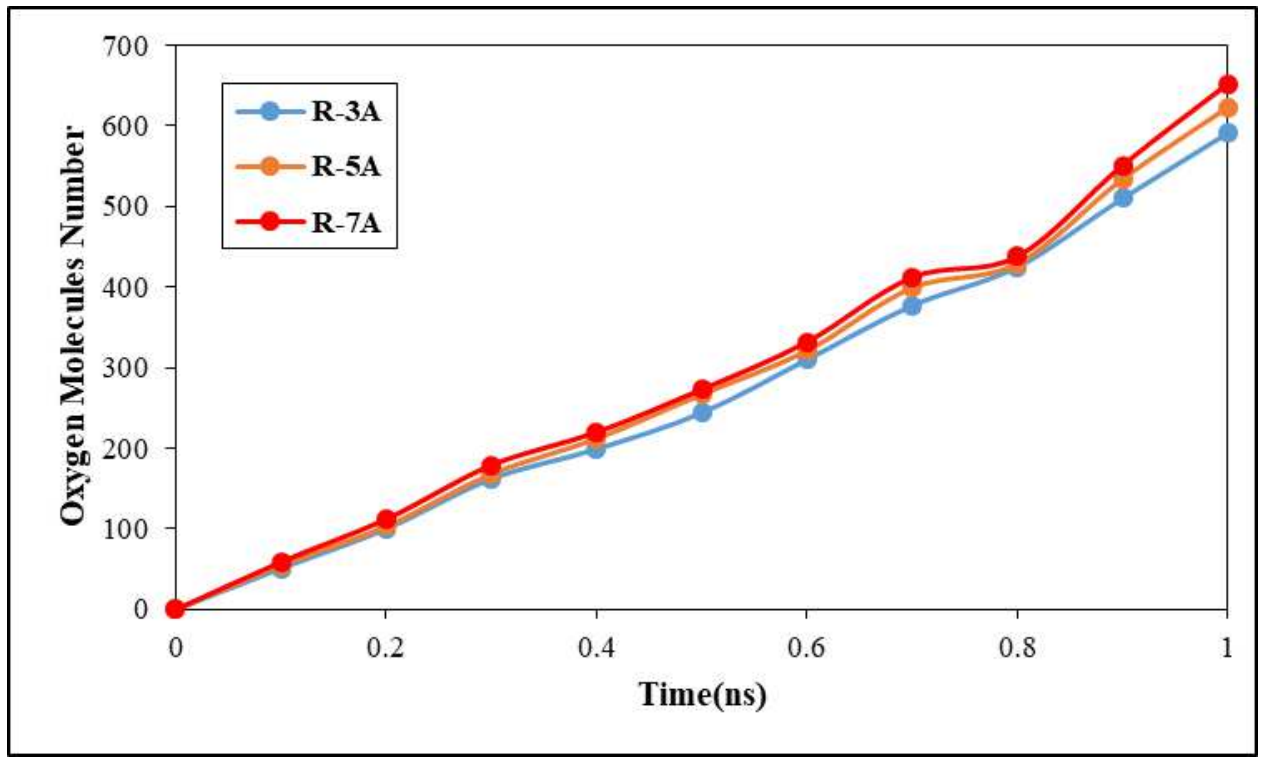

Figure 10. Number of $\mathrm{O}_{2}$ molecules which passed from pristine graphene membrane as a function of graphene layers porous size $(\mathrm{R})$.

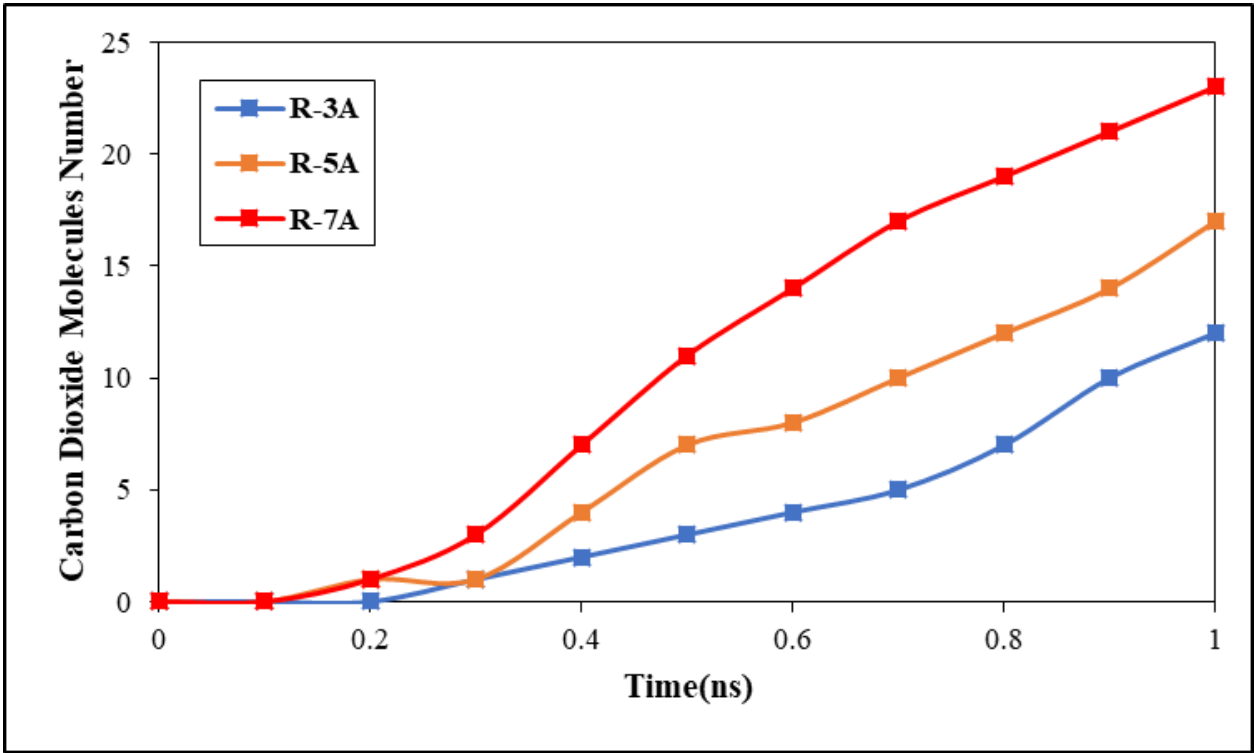

Figure 11. Number of $\mathrm{CO}_{2}$ molecules which passed from pristine graphene membrane as a function of graphene layers porous size $(\mathrm{R})$. 

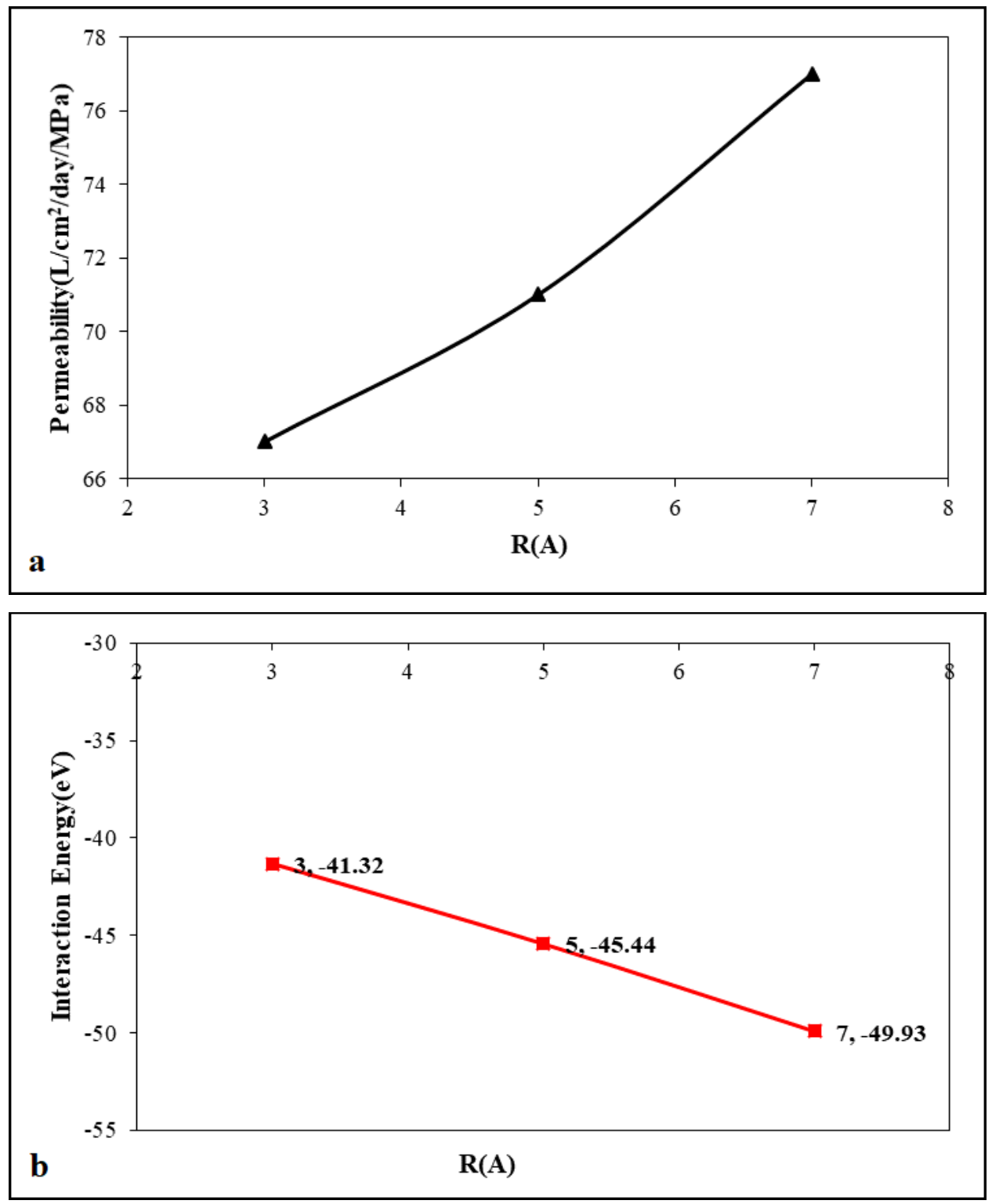

Figure 12. a) Permeability of graphene-based membrane as a function of graphene layers porous size (R).

b) Interaction energy between atomic membrane and gas system as a function of $\mathrm{R}$ parameter.

Table 4. Number of $\mathrm{O}_{2}$ and $\mathrm{CO}_{2}$ molecules which passed from graphene-based membrane and membrane permeability as a function of graphene layers porous size (R).

\begin{tabular}{|c|c|c|c|}
\hline $\begin{array}{c}\text { Graphene Layers } \\
\text { Porous Size (̊) }\end{array}$ & $\begin{array}{c}\text { Number of Passed } \\
\mathbf{O}_{\mathbf{2}} \text { Molecules }\end{array}$ & $\begin{array}{c}\text { Number of Passed } \\
\mathbf{C O}_{\mathbf{2}} \text { Molecules }\end{array}$ & Permeability(L/cm $/$ day/MPa) \\
\hline $\mathbf{3}$ & 591 & 12 & 67 \\
\hline $\mathbf{5}$ & 623 & 17 & 71 \\
\hline $\mathbf{7}$ & 652 & 23 & 77 \\
\hline
\end{tabular}




\section{Conclusion}

We use Molecular Dynamics (MD) simulations to describe the behavior of multilayer (3layers) graphene membrane in gas mixture purification process $\left(\mathrm{O}_{2}\right.$ molecules purification from $\mathrm{O}_{2}-\mathrm{CO}_{2}$ gas system). Our important computational results from MD simulations are as following:

A. DREIDING and Tersoff force-fields are appropriate functions to MD simulation of graphene-based membrane and $\mathrm{O}_{2}-\mathrm{CO}_{2}$ gas mixture inside MD box.

B. MD outputs predicted the number of $\mathrm{O}_{2}$ and $\mathrm{CO}_{2}$ molecules which passed from graphene membrane are 652 (97.31\% ratio) and 23 (32.86\% ratio) molecules after $\mathrm{t}=1 \mathrm{~ns}$.

C. Numerically, the permeability of graphene membrane reach to $77 \mathrm{~L} / \mathrm{cm}^{2} / \mathrm{day} / \mathrm{MPa}$ value by atomic structure optimization.

D. Increasing of graphene atomic layers distance in simulated membrane, cause the accuracy improve and performance speed decrease in atomic purification process. Numerically, interaction energy between membrane and gas mixture converged to $-32.09 \mathrm{eV}$ by this atomic process done.

E. Increasing of graphene atomic layers porous, cause the accuracy decrease and performance speed increase in atomic purification process. Numerically, interaction energy between membrane and gas mixture converged to $-49.93 \mathrm{eV}$ by this atomic process done.

These MD simulation results was shown that, the atomic arrangement of carbon atoms in graphene-based membrane can be improve the purification process accuracy or speed. Practically, these estimated results can be implemented in various purification process to optimize the industrial application efficiency.

\section{Declarations}

Funding: The authors declare that they don't received any fund for current research. 
Conflicts of interest/Competing interests The authors declare that they have no conflicts of interest.

Ethics approval N/A

Consent to participate N/A

Consent for publication N/A

Availability of data and material Data available on request from the authors.

Code availability LAMMPS main inputs available on request from the authors.

Authors' contributions Mostafa Jafari: Designed the analysis, Performed the analysis; Wrote the paper. Roozbeh Sabetvand: Designed the analysis, proof reading.

\section{References}

[1] Bunch, J. S., Verbridge, S. S., Alden, J. S., van der Zande, A. M., Parpia, J. M., Craighead, H. G., \& McEuen, P. L. (2008). Impermeable Atomic Membranes from Graphene Sheets. Nano Letters, 8(8), 2458-2462. doi:10.1021/n1801457b

[2] Gilje, S., Han, S., Wang, M., Wang, K. L., \& Kaner, R. B. (2007). A Chemical Route to Graphene for Device Applications. Nano Letters, 7(11), 3394-3398. doi:10.1021/n10717715.

[3] Schniepp, H. C., Li, J.-L., McAllister, M. J., Sai, H., Herrera-Alonso, M., Adamson, D. H., ... Aksay, I. A. (2006). Functionalized Single Graphene Sheets Derived from Splitting Graphite Oxide. The Journal of Physical Chemistry B, 110(17), 8535-8539. doi:10.1021/jp060936f.

[4] Zhou, F., Fathizadeh, M., \& Yu, M. (2018). Single- to Few-Layered, Graphene-Based Separation Membranes. Annual Review of Chemical and Biomolecular Engineering, 9(1), 17-39. doi:10.1146/annurev-chembioeng-060817-084046.

[5] Geim, A. K.; Novoselov, K. S. (26 February 2007). "The rise of graphene". Nature Materials. 6 (3): 183-191. arXiv:cond-mat/0702595. Bibcode:2007NatMa...6..183G. doi:10.1038/nmat1849.

[6] Peres, N. M. R.; Ribeiro, R. M. (2009). "Focus on Graphene". New Journal of Physics. 11 (9): 095002. Bibcode:2009NJPh...11i5002P. doi:10.1088/1367-2630/11/9/095002.

[7] Boehm, H. P.; Setton, R.; Stumpp, E. (1994). "Nomenclature and terminology of 
graphite intercalation compounds" (PDF). Pure and Applied Chemistry. 66 (9): 18931901. doi:10.1351/pac199466091893.

[8] Peter J. F. Harris (2018): "Transmission electron microscopy of carbon: A brief history". C - Journal of Carbon Research, volume 4, issue 1, article 4 (17 pages). doi:10.3390/c4010004.

[9] Nair, R. R.; Blake, P.; Grigorenko, A. N.; Novoselov, K. S.; Booth, T. J.; Stauber, T.; Peres, N. M. R.; Geim, A. K. (6 June 2008). "Fine Structure Constant Defines Visual Transparency of Graphene". Science. 320 (5881): 1308. arXiv:0803.3718. Bibcode:2008Sci...320.1308N. doi:10.1126/science.1156965.

[10] Lee, Changgu (2008). "Measurement of the Elastic Properties and Intrinsic Strength of Monolayer Graphene". Science. 321 (385): 385-388. Bibcode:2008Sci...321..385L. doi:10.1126/science.1157996.

[11] Tsang, A. C. H., Kwok, H. Y. H., \& Leung, D. Y. C. (2017). The use of graphenebased materials for fuel cell, photovoltaics, and supercapacitor electrode materials. Solid State Sciences, 67, A1-A14. doi:10.1016/j.solidstatesciences.2017.03.015.

[12] Qu, L., Liu, Y., Baek, J.-B., \& Dai, L. (2010). Nitrogen-Doped Graphene as Efficient Metal-Free Electrocatalyst for Oxygen Reduction in Fuel Cells. ACS Nano, 4(3), 13211326. doi:10.1021/nn901850u.

[13] Vivekchand, S. R. C., Rout, C. S., Subrahmanyam, K. S., Govindaraj, A., \& Rao, C. N. R. (2008). Graphene-based electrochemical supercapacitors. Journal of Chemical Sciences, 120(1), 9-13. doi:10.1007/s12039-008-0002-7.

[14] Zhang, L. L., Zhou, R., \& Zhao, X. S. (2010). Graphene-based materials as supercapacitor electrodes. Journal of Materials Chemistry, 20(29), 5983. doi:10.1039/c000417k.

[15] Li, H., Zou, L., Pan, L., \& Sun, Z. (2010). Novel Graphene-Like Electrodes for Capacitive Deionization. Environmental Science \& Technology, 44(22), 8692-8697. doi:10.1021/es101888j.

[16] Zhang, D., Yan, T., Shi, L., Peng, Z., Wen, X., \& Zhang, J. (2012). Enhanced capacitive deionization performance of graphene/carbon nanotube composites. Journal of Materials Chemistry, 22(29), 14696. doi:10.1039/c2jm31393f.

[17] Yin, H., Zhao, S., Wan, J., Tang, H., Chang, L., He, L., ... Tang, Z. (2013). ThreeDimensional Graphene/Metal Oxide Nanoparticle Hybrids for High-Performance 
Capacitive Deionization of Saline Water. Advanced Materials, 25(43), 6270-6276. doi:10.1002/adma.201302223.

[18] Cohen-Tanugi, D., \& Grossman, J. C. (2012). Water Desalination across Nanoporous Graphene. Nano Letters, 12(7), 3602-3608. doi:10.1021/n13012853.

[19] You, Y., Sahajwalla, V., Yoshimura, M., \& Joshi, R. K. (2016). Graphene and graphene oxide for desalination. Nanoscale, 8(1), 117-119. doi:10.1039/c5nr06154g.

[20] Cohen-Tanugi, D., Lin, L.-C., \& Grossman, J. C. (2016). Multilayer Nanoporous Graphene Membranes for Water Desalination. Nano Letters, 16(2), 1027-1033. doi:10.1021/acs.nanolett.5b04089.

[21] Xue, C., Wang, X., Zhu, W., Han, Q., Zhu, C., Hong, J., ... Jiang, H. (2014). Electrochemical serotonin sensing interface based on double-layered membrane of reduced graphene oxide/polyaniline nanocomposites and molecularly imprinted polymers embedded with gold nanoparticles. Sensors and Actuators B: Chemical, 196, 57-63. doi:10.1016/j.snb.2014.01.100.

[22] Asgari, A., Nguyen, Q., Karimipour, A., Bach, Q.-V., Hekmatifar, M., \& Sabetvand, R. (2020). Investigation of additives nanoparticles and sphere barriers effects on the fluid flow inside a nanochannel impressed by an extrinsic electric field: A molecular dynamics simulation. Journal of Molecular Liquids, 114023. doi:10.1016/j.molliq.2020.114023.

[23] Ashkezari, A. Z., Jolfaei, N. A., Jolfaei, N. A., Hekmatifar, M., Toghraie, D., Sabetvand, R., \& Rostami, S. (2019). Calculation of the thermal conductivity of Human Serum Albumin (HSA) with equilibrium/non-equilibrium molecular dynamics approaches. Computer Methods and Programs in Biomedicine, 105256. doi:10.1016/j.cmpb.2019.105256.

[24] Ghanbari, A., Warchomicka, F., Sommitsch, C., \& Zamanian, A. (2019). Investigation of the Oxidation Mechanism of Dopamine Functionalization in an AZ31 Magnesium Alloy for Biomedical Applications. Coatings, 9(9), 584. doi:10.3390/coatings9090584.

[25] Sabetvand, R., Ghazi, M.E. \& Izadifard, M. (2020). Studying temperature effects on electronic and optical properties of cubic $\mathrm{CH} 3 \mathrm{NH} 3 \mathrm{SnI} 3$ perovskite. J Comput Electron 19, 70-79. doi:10.1007/s10825-020-01443-3.

[26] Cohen-Tanugi, D., \& Grossman, J. C. (2012). Water Desalination across Nanoporous Graphene. Nano Letters, 12(7), 3602-3608. doi:10.1021/nl3012853.

[27] Cohen-Tanugi, D., Lin, L.-C., \& Grossman, J. C. (2016). Multilayer Nanoporous Graphene Membranes for Water Desalination. Nano Letters, 16(2), 1027-1033. doi:10.1021/acs.nanolett.5b04089. 
[28] Kim, H. W., Yoon, H. W., Yoon, S.-M., Yoo, B. M., Ahn, B. K., Cho, Y. H., Park, H. B. (2013). Selective Gas Transport Through Few-Layered Graphene and Graphene Oxide Membranes. Science, 342(6154), 91-95. doi:10.1126/science.1236098.

[29] Wang, J., Zhang, P., Liang, B., Liu, Y., Xu, T., Wang, L., ... Pan, K. (2016). Graphene Oxide as an Effective Barrier on a Porous Nanofibrous Membrane for Water Treatment. ACS Applied Materials \& Interfaces, 8(9), 6211-6218. doi:10.1021/acsami.5b12723.

[30] Plimpton, S. (1995). Fast Parallel Algorithms for Short-Range Molecular Dynamics. Journal of Computational Physics, 117(1), 1-19. doi:10.1006/jcph.1995.1039.

[31] Plimpton, S. J., \& Thompson, A. P. (2012). Computational aspects of many-body potentials. MRS Bulletin, 37(05), 513-521. doi:10.1557/mrs.2012.96.

[32] Aktulga, H. M., Fogarty, J. C., Pandit, S. A., \& Grama, A. Y. (2012). Parallel reactive molecular dynamics: Numerical methods and algorithmic techniques. Parallel Computing, 38(4-5), 245-259. doi:10.1016/j.parco.2011.08.005.

[33] Brown, W. M., Wang, P., Plimpton, S. J., \& Tharrington, A. N. (2011). Implementing molecular dynamics on hybrid high performance computers - short range forces. Computer Physics Communications, 182(4), 898-911. doi:10.1016/j.cpc.2010.12.021.

[34] Stukowski, A. (2009). Visualization and analysis of atomistic simulation data with OVITO-the Open Visualization Tool. Modelling and Simulation in Materials Science and Engineering, 18(1), 015012. doi:10.1088/0965-0393/18/1/015012.

[35] D. C. Rapaport. (2004). The Art of Molecular Dynamics Simulation (2nd. ed.). Cambridge University Press, USA.

[36] Nosé, S (1984). "A unified formulation of the constant temperature moleculardynamics methods". Journal of Chemical Physics. 81 (1): 511-519. Bibcode:1984JChPh..81..511N. doi:10.1063/1.447334.

[37] Hoover, William G. (Mar 1985). "Canonical dynamics: Equilibrium phase-space distributions". Phys. Rev. A. 31 (3): 1695-1697. Bibcode:1985PhRvA..31.1695H. doi:10.1103/PhysRevA.31.1695.

[38] Mayo, S. L., Olafson, B. D., \& Goddard, W. A. (1990). DREIDING: a generic force field for molecular simulations. The Journal of Physical Chemistry, 94(26), 8897-8909. doi:10.1021/j100389a010.

[39] Tersoff, J. (1988). New empirical approach for the structure and energy of covalent systems. Physical Review B, 37(12), 6991-7000. doi:10.1103/physrevb.37.6991.

[40] Lennard-Jones, J. E. (1924), "On the Determination of Molecular Fields", Proc. R. Soc. Lond. A, 106 (738): 463-477, Bibcode:1924RSPSA.106..463J, 
doi:10.1098/rspa.1924.0082.

[41] Cohen-Tanugi, D., \& Grossman, J. C. (2014). Water permeability of nanoporous graphene at realistic pressures for reverse osmosis desalination. The Journal of Chemical Physics, 141(7), 074704. doi:10.1063/1.4892638.

[42] Nair, R. R., Wu, H. A., Jayaram, P. N., Grigorieva, I. V., \& Geim, A. K. (2012). Unimpeded Permeation of Water Through Helium-Leak-Tight Graphene-Based Membranes. Science, 335(6067), 442-444. doi:10.1126/science.1211694. 